\title{
Protocol on stratigraphic micro-samples from surface finishes obtained at historic-archaeological buenos aires walls for their conservation, technological \& archaeometrical analysis
}

\begin{abstract}
This paper presents the trials to establish a protocol to perform and preserve the inclusion in acrylic resin of stratigraphic micro- samples from surface finishes obtained at historicarchaeological brick walls. The aim is to highlight the importance of samples conservation status, same as describing technological and archaeometrical studies of ceramic materials in the Historical Archeology. These stratigraphic micro-samples within acrylic resin could be further analyzed with optical and/or physical-chemical characterization techniques. The surface finishes of brick walls are generally made of various materials framed within a broad concept of ceramic materials, such as: clay, lime and various pigment mixtures, among the main ones. The technological and archaeometrical analysis based on the stratigraphic micro-samples allows the recording and characterizing relationships of strata formed by the progressive accumulation of the different layers of surface and environmental finishes. In addition, this analysis extends to the application techniques for micro-structural, morphological, physical and chemical characterization.
\end{abstract}

Keywords: ceramic technology, archaeometry, ceramic materials, stratigraphic microsamples, historical archeology, archeology of architecture
Volume 4 Issue 4 - 2019

\author{
López Mariel Alejandra \\ Department of Anthropological Sciences, Institute of \\ Archaeology, University of Buenos Aires/National Council of \\ Scientific and Technical Research CONICET,Argentina \\ Correspondence: López Mariel Alejandra, Institute of \\ Archeology, Department of Anthropological Sciences, University \\ of Buenos Aires/National Council of Scientific and Technical \\ Research, 3rd floor, office 3 (Cl002AB), Autonomous City of \\ Buenos Aires, Argentinian Republic, Argentina, Tel (54II) 5287- \\ 2632, ORCID 0000-000I-6517-8385, \\ Emailmarielarqueologia@yahoo.com.ar
}

Received: August 16, 2019 | Published: August 30, 2019

\section{General introduction to history of the inclusion of micro-samples and the observation of stratigraphic micro-samples}

Since the beginning of the last century, with the contributions from the Arts Science, the Conservation and Restoration fields, we have analyzed the small representations of the layers of paintings or stratigraphic micro-samples. ${ }^{1}$ Despite many authors pointing out the work by Plesters ${ }^{2}$ as a pioneer, others reinforced the importance of the work by Sneyers and Thissen, ${ }^{3}$ for the preparation of sections to carry out this type of study, being Coremans and Thissen ${ }^{4}$ who introduced the first study on paintings. In fact, these are generally pieces of "art" that are part of important collections at museums, but also paintings of building-walls of high historical or heritage value. Following available sampling guidelines, samples would be obtained out of degraded pieces of work either in the restoration or conservation status. In this sense, the analysis of characterization of the different layers pursued by almost single purpose the determination of the materials used in order to find compatible compositions during the process of restoration-conservation of the work, which was also carried out according to different criteria according to the times and schools. Since then and up to the present, the ways of treating these small samples have been changing according to the technological advances and the study objectives. Indeed, destructive identification techniques predominated, for example, by means of different chemical reagents. Consequently, although stratigraphic micro-samples were taken or, as the Spanish-speaking authors point out, samples in vertical section, feasible to be observed and analyzed in their technical aspects under microscopy, the chemical analyzes many times carried out destroyed the possibility of keep preserving said samples.
The method of inclusion for the micro-samples would also vary according to the times and the identification of new materials. As an example, some micro-samples started to appear in the form of small blocks of resin (epoxy, acrylic or polyester) obtained from different types of molds (poly-methyl methacrylate or silicone). The epoxy resin or poly-epoxide is a thermostable polymer. The first commercial attempts of production started in 1927 in the United States. However, a Swiss and an American introduced the first attempts of bis-phenolresin based synthesis in 1936. The work of the Swiss was licensed in Switzerland, and quickly became one of the three largest global manufacturers of epoxy resins, commercializing them under the name of Araldite. Towards the end of 1990s, the Swiss business was acquired by Shell. Acrylic resin was developed in 1928 in several laboratories and introduced to the market in 1933. Acrylic resin is a polymer of methyl methacrylate for which multiple terms are often mentioned in the literature as equivalent, such as: acrylic, methacrylate and methyl methacrylate although the most appropriate equivalent would be polymethyl methacrylate or methyl poly-methacrylate.

Polyester resin was introduced to the market in the 1940s and was quickly applied for the inclusion of samples from the natural world. Although it was demonstrated that polyester resins are not the most efficient materials for the conservation of micro-samples containing organic elements, they continued in use at least towards the end of the last century, particularly in museums. The process would usually follow a pattern, including the following: once the process of total curing of the inclusion resin was developed, a long block of resin containing several samples was cut, rough and sanded in a metallographic polisher or different sandpaper grain sizes to obtain the micro-stratigraphic view. This last step was repeated as many times as required in order to obtain what the literature on this subject would call stratigraphic-micro-sections of 50 microns and above. 
In spite of this background, it has been over the last two decades that this technique has been further developed, improved and extended to all kind of cultural goods. In this sense, we can include both microsamples of objects that are part of archaeological records and parietal art generally known as "rock art", and even walls of historic buildings whether or not they were patrimonial. It is interesting to point out that in the case of the historical walls and since the beginning of the 1990 s, studies of the walls-finishing stratigraphy in the form of coves or windows ${ }^{5}$ whether vertical or horizontal, were linked to restoration and architecture in both America and Europe. This technique was also compared to the archaeological stratigraphy, whether or not that procedure was carried out by archaeologists (Figures 1\&2). As pointed out by Vallín and Falcheti, ${ }^{5}$ in many cases the study of surface finishes or mural painting mimics the work by the archaeologist, who analyzes from the most recent to the oldest layers to investigate the materials, techniques, colors, designs (thematic ones in the case of finding motives), treatments given to walls and their evolutionary process. In this regard, this kind of analysis is usually performed not only by conservators or restorers but also by archaeologists and architects. In this sense, the aforementioned authors also pointed out the importance of carrying out, at least in some cases, inclusion of samples in acrylic resin in order to observe them under a microscope and clear any doubts.

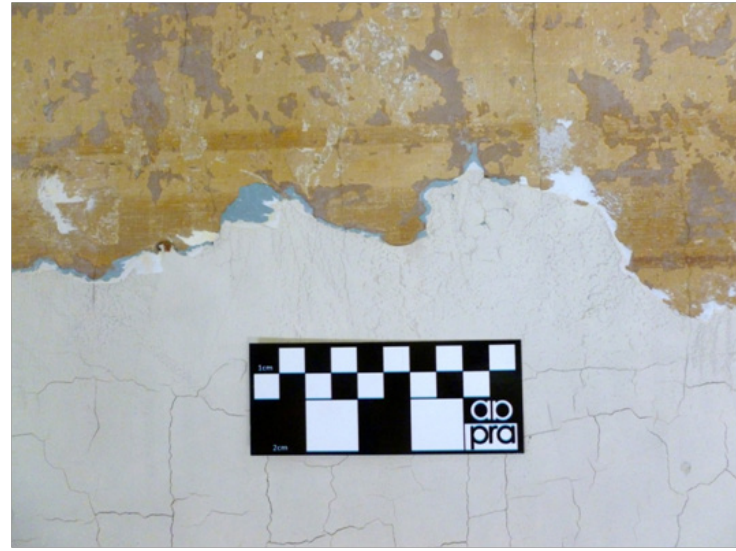

Figure I Wall with deteriorated sector in one of the corridors of our research institute

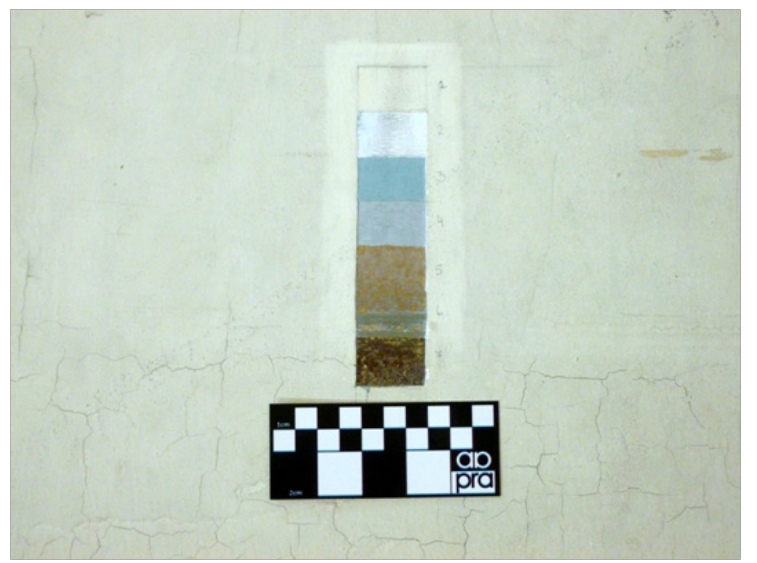

Figure 2Typical window made by the Conservator Norma Pérez and showing different layers of wall paint superimposed on one of the walls of our research institute located in the City of Buenos Aires.

\section{Material and methods}

\section{The case of study and objective of this work}

This work is part of the case study of Historical Archeology that we are currently developing in the San Vicente Party, Buenos Aires province, Argentina (Figure 3). In two of the indicated archaeological sites: San Vicente 2 (SV2) and San Vicente 3 (SV3) and within the area that constitutes what was the old town of San Vicente, after photographing and raising the plants of the remains of buildings present in them, there were two problems. The first of them was how to proceed to record the different types of deterioration of the constructions in situ, as well as to take and preserve samples of the walls and, in particular, not only of their bricks, as is traditionally customary in Historical Archeology, but also of mortars and surface finishes including natural coverage. The second one was how to read and analyze the different strata of the walls and events or constructive episodes, a subject that will be discussed in an upcoming work. With regard to the first of the problems, which will be treated methodologically in this work, together with the photographic record of the different natural and/or anthropic finishes of the walls, we first registered the deteriorations in situ, including by Universal Serial Bus (USB) Microscopy (Figures 4\&5) and then, considering its variability, we took samples of loose or surface bricks, as well as small samples of the different types of mortars and surface finishes and coverage contained in them (Figures 6\&7).

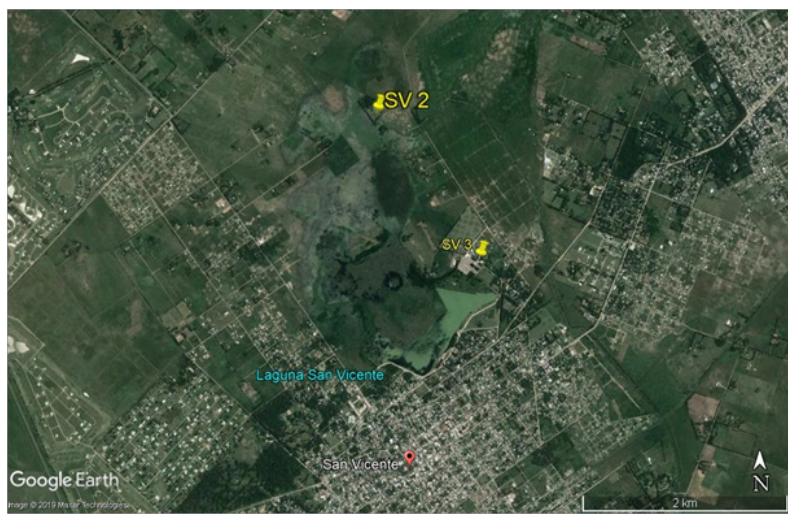

Figure 3 Location map of the San Vicente Party in the Province of Buenos Aires, Argentina with two of the archaeological sites under study around the old town.

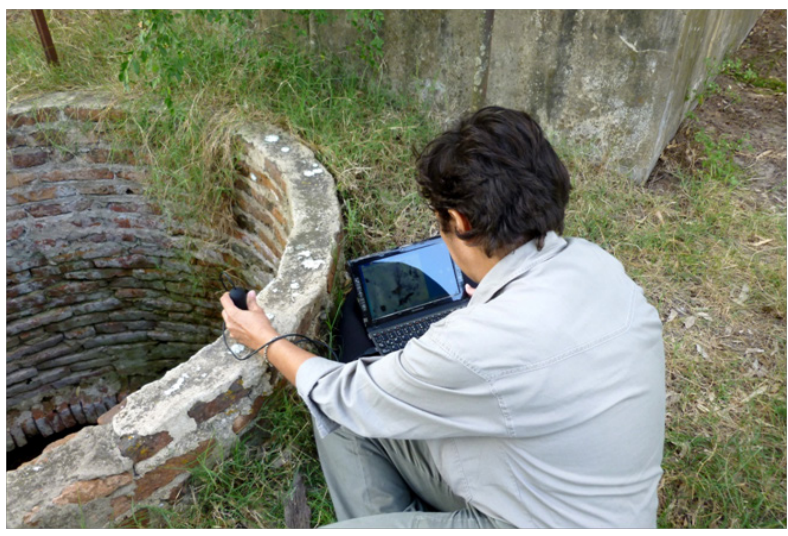

Figure 4 Dr. Mariel A López recording by USB microscopy the deterioration of the bricks of the edge of large water well located at the archaeological site SV2. 


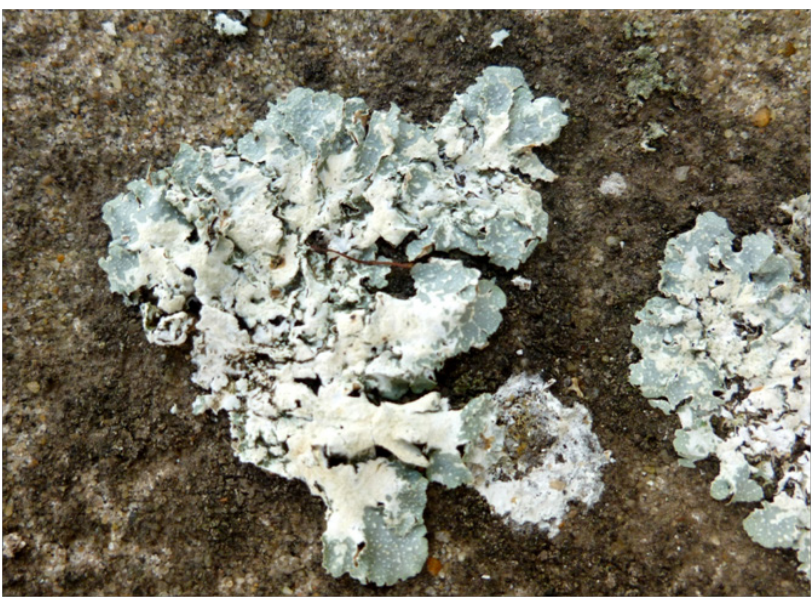

Figure 5 Image at $20 \times$ of fungi on the surface of one of the bricks of the water well located in the archaeological site SV2.

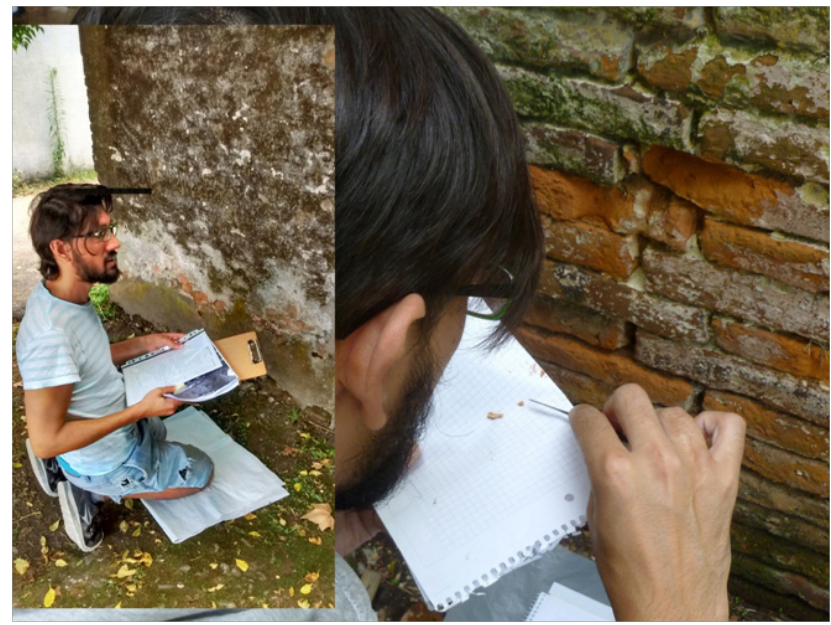

Figure 6 Magister Cristian López Rey sampling with scalpel the different surface finishes previously mapped in survey cards on wall I of the archaeological site SV3.

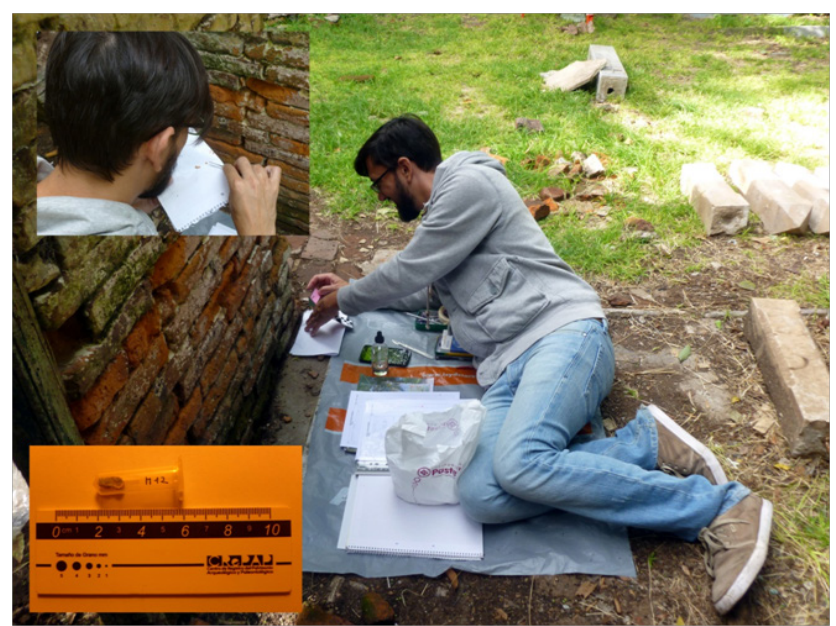

Figure 7 Magister Cristian López Rey sampling with scalpel, and occasionally using a consolidator (Paraloid), the different surface finishes previously mapped in survey cards on wall 4 of the archaeological site SV3. They were stored in small containers called eppendorf.
Once in the archaeological cabinet, the problem that was presented was to study the micro-stratigraphy of the surface finishes, in the case of the presence of plaster, as well as natural coverage. In this last sense, this work aims to present then the results achieved by an experimental trial to be able to carry out an adequate support in order to achieve a better analysis and subsequent conservation of the stratigraphic micro-samples taken in the field. As archaeologists, the challenge then was not only to prepare micro samples of historic walls included in a support, so as to be able to observe the micro stratigraphy or the succession and relationships between strata formed by the progressive accumulation of different layers of finishes of surface and/or environmental. It was also the case of achieving a protocol for the preparation of stratigraphic micro-samples that could be replicated in other cases and that allowed them to be preserved in order to later perform the physic-chemical characterization using more advanced techniques than optical microscopy, such as, for example, by using of USB Microscope and Tri Ocular Microscope (TM). The idea of preserving the micro-samples in supports allows us to analyze them as often as necessary with other types of equipment such as the Confocal Microscope (CM) and/or the Scanning Electronic Microscope (SEM).

Indeed, through these analytical tools, already widely used in Archaeometry, it is possible to observe, first, the micro-structural and / or micro-morphological characteristics of the different layers or strata that make up a small sample of the finish of a wall historical. If we also add to the analysis with the SEM, the qualitative and quantitative analysis of an Energy Dispersive X-Ray Spectrometer (EDS), it is also possible to characterize each of these strata or microforms at the elementary level. The latter is important in determining more accurately the materials used in surface finishes in cases of restoration, as well as the natural processes suffered by layers that can protect and/or damage surfaces. The objective was then to achieve a stratigraphic micro-sample included in resin that would preserve the relationships of the different layers of natural residues or intentional surface finishes, as well as the micro-structural, micro-morphological and technical characteristics that should be known before performing a physical-chemical characterization of its elements or compounds. In order to achieve the desired stratigraphic micro-sample we carried out an experimental test with a micro sample of a wall at the end of the 19 th century to beginning of 20th century of the City of Buenos Aires, in order to develop a protocol to follow with the archaeological macro and micro samples obtained in the town of San Vicente.

\section{More contemporary methodological background of inclusion stratigraphic micro-sample for analysis}

As noted in the section on historical background, the reading of the mentioned works has been important. Especially as regards the different ways in which micro stratigraphic micro-samples have been prepared and used throughout history. However, it is in Spain where we have predominantly found the first antecedents in the use of stratigraphic micro-samples applied not only to the study of the various layers of painting of a work of art, as understood by Western culture, but also to rock art or parietal art or for the study of the finishing of historic walls. Thus, for example, the use of stratigraphic micro-samples of pictorial layers with part of the support of rock art by colleagues of the University of Valencia is highlighted, who already in the early 1990s included them directly in methacrylate to then cut and sand them, including in thin sections, to analyze them under the optical and Petrographic Microscope (PM), among other analyzes. ${ }^{6}$ The interesting thing about the work of these authors is that 
they clearly take up a previously proposed methodology in the field of the Conservation of Cultural Goods at least a decade before.?

With regard to the studies of surface finishing's of walls, or also called plasters, as well as regarding the beginning of the importance of their study, ${ }^{5}$ it is also interesting to highlight here the work of the colleagues of the Andalusian Institute of Historical Heritage. ${ }^{8}$ In effect, in the Spanish-speaking world this work speaks on the importance that these analyses have not only from the technological point of view but also, when facing the archaeological study of the architecture of historical buildings. In fact, although these archaeologists study a case that will be later restored, along with the stage of historical documentation study, they approach to the stratigraphic study of architecture and allocate a portion of those analyzes to what is known as the study of the surface finishes of the walls, with the taking of samples for later analysis in the laboratory. Although it is not exactly the same technique proposed here to conserve and analyze the stratigraphic micro samples, in some way this school of work, like that of Vallín and Falchetti, ${ }^{5}$ anticipate the importance of technical analysis and not only compositional of the different layers that can be part of the different finishes of the same wall in different sectors of the surviving surfaces. That is why they propose the inclusion in resins of some of the samples investigated.

At the level of Latin American and Regional Archaeology, we also want to highlight here the background of the preparation of micro sample inclusions for stratigraphic analysis, since these are our closest examples. Among the preliminary works that begin to be concerned not only with the analysis of layers of archaeological painting in stratigraphic micro-samples, but also by establishing a sampling protocol and preparation of the micro samples, the work of Sepúlveda and Laval ${ }^{9}$ undoubtedly stands out. In fact, it is only a little less than a decade ago that the region mentions the possibility of making stratigraphic micro-samples of paint layers of archaeological goods included in resins. Although the work of Sepúlveda and Laval ${ }^{9}$ does not give details of the technique applied to the study of rock art, nor results of the stratigraphic micro-samples analysis are shown, this work it is emphases the need of this type of study to complement the first analyzes under Optical Microscopy of the samples as they are obtained in the field. This type of early interest in Chile is born not only from the hand of specialists in rock art but also from the hand of conservators. Above all, the School of the National Center for Conservation and Restoration (CNCR), where the analysis of pictorial layers was already being carried out in the context of research focused on the restoration and conservation of works of patrimonial interest ${ }^{10}$ also including cases of ceramics.

In Argentine Archeology, the inclusion of micro samples in resins has begun to be used recently in what some authors have called the perspective of "Art Archaeometry". ${ }^{11}$ This is because the inclusions of micro samples of finishes or pictorial layers has begun to be used and not only applied to the study of objects considered from the History of Art and Conservation-Restoration ${ }^{12}$ but, also, to archaeological products (rock art and furniture objects in general). This archaeometric perspective also takes into account what Sepúlveda had also called "color technology"13 and refers to all the technical aspects involved in the study of the different layers of paint that can be observed in rock art, in the finish of an archaeological object or, as in our case, in that of a historic wall. From then on, the micro samples included and in stratigraphic view have not only begun to be applied in Argentina to rock art. ${ }^{14}$ This technique also began to be applied on micro samples of archaeological furniture objects, especially in cases of samples taken from surface finishes of ceramic pieces. In this last sense we highlight in our country our experience of sampling on ceramic pieces of collection, such as ceramic queros vessels housed in the Eduardo Casanova Museum, Tilcara, province of Jujuy (Figure 8), work that is part of another case of study, as well as the publication of Marte, Acevedo and Mastrángelo, ${ }^{15}$ where the tricolor surface finish of a Northwest ceramic type in stratigraphic micro-sample is studied. Finally, the micro-stratigraphic technique of ceramic surface finishes has also been used successfully in the work of López, ${ }^{16}$ in which the scope of this technique could be appreciated on a type of ceramic that had previously been considered as a material without finishing of any surface. ${ }^{16}$

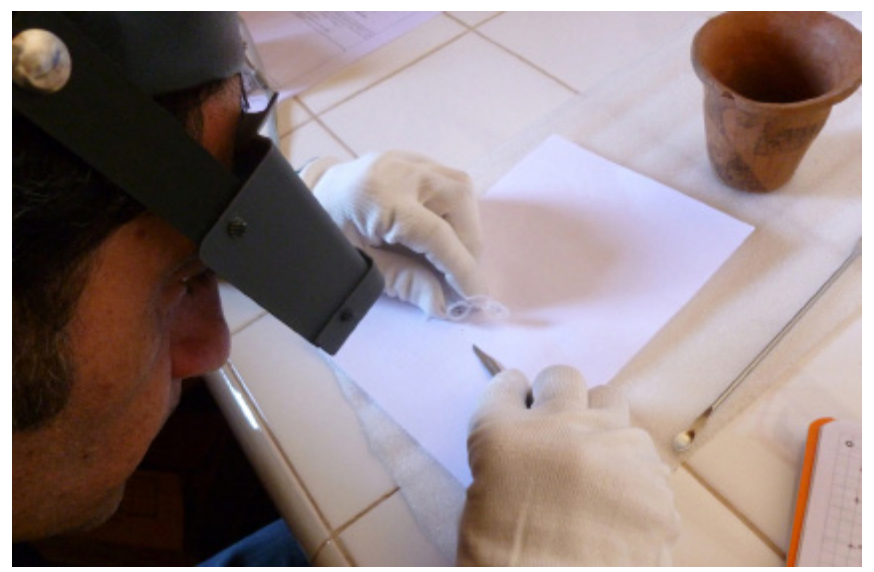

Figure 8 In this image, we can view Dr. Marte with the elements of the registration and sampling of a polychrome ceramic quero vessel, as well as the storage of the micro sample, about the size of a pinhead, inside an eppendorf container.

\section{Experimental test}

In order to comply with the stated objective, and based on the technique learned with the case studies cited in the previous section, this work continued with the development of an experimental design previously tested with silicone molds on surface finishes of 5 ceramic samples. ${ }^{16}$ In this case, as was already expressed, the test was made from the surface finishes of wall's samples from a house at the end of 19th century to the beginning of the 20th century in Buenos Aires City.

In this way, and through a TM of up to $80 \mathrm{X}$, we could achieve:

1. The determination more reliably the numbers of strata (pictorial and natural layers) that constitute the stratigraphic micro-surface finish sample

2. The identification of type (s) of preparation (including the possibility of an initial preparation base),

3. The indicators of the application form (s) of each one of them

4. The identification of existence and quantity of repaints

Finally and as required, specimens would undergo further microscopic analysis. The experimental procedure began with careful bibliographic background review regarding methods available to obtain specimens that would contain micro samples same as different qualities of the materials utilized for that. It was also observed and examined first in a macroscopic way, the historical wall but without archaeological interest to be sampled in this trial, especially its state of conservation and/or alteration. After the experience published 
in López, ${ }^{16}$ this experiment was carried out with 5 other nonarchaeological samples from different sectors of a wall of a house from the end of the 19th century to beginning of 20th century, located in a peripheral neighborhood of the city of Buenos Aires, Argentina. According to its typology, this house, currently recycled, responds to the typology known as "casa chorizo de esquina".

The micro sample included in the most successful acrylic resin that we show here comes from the surface finish of the corner of an originally external wall (of the room that communicated with the patio through which the kitchen and bathroom were accessed) and that, currently, it is inside the family home. Due to the humidity of the foundations, this wall was in different stages, including the loss of plaster sectors (Figure 9). For the experimental test, the same variables were re-measured as in the case of previously made stratigraphy micro-ceramic samples, ${ }^{16}$ as well as the same type of acrylic resin marketed for dental use. They are detailed below in order to continue replicating the trial and achieve replicable parameters:

\section{Different instruments for obtaining the micro sample}

\section{Different types of molds}

\section{Different proportions of powder and catalyst}

\section{Ambient temperature}

5. Optimum moment of placement of the micro sample in the mold

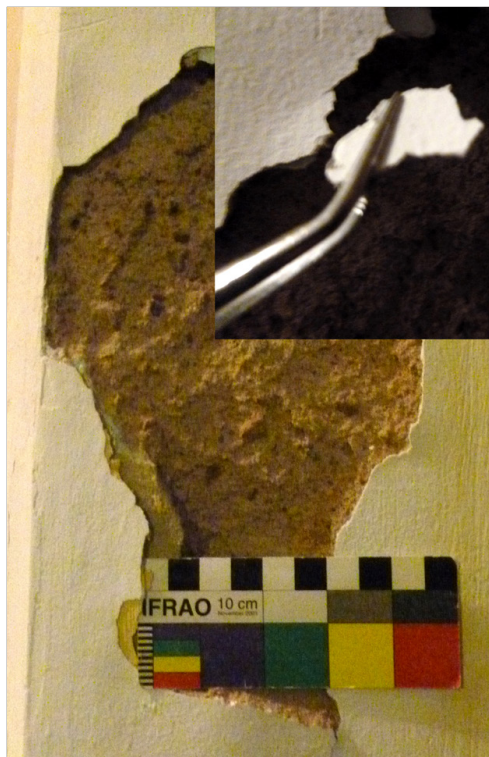

Figure 9 Dr. Mariel A. López taking a micro sample of Buenos Aires wall for this experimental test.

\section{Setting or curing time}

The obtaining of the micro sample, which can be taken with a scalpel or cotton clip, depending on the case, involves a section of the surface finish of the wall that, although very small, is representative of what we intend to analyze. In this case it was: superposition of observable strata as pictorial layers or of different types of finishes, techniques used for their application, composition of the same, alterations and state of conservation, among the main characteristics. Regarding the selection of the type of mold suitable to include this type and sizes of samples we do not have direct antecedents. However, and in accordance with our previous experience with ceramic micro samples, ${ }^{16}$ we know that there are very well developed general antecedents based on transparent methacrylate (methyl poly methacrylate) and very small molds, between 8 and $10 \mathrm{~mm}$ of depth and $10 \mathrm{~mm}$ in diameter. ${ }^{17,18}$ Even, the case of use of plastic pillboxes and even blister packs disused. ${ }^{15}$ According to our experience with acrylic resins, even those of cold curing, we know that these easily melt semi-rigid molds, including many of the plastic materials used for pill boxes and blisters manufactured, usually with thermoformed plastics. Therefore, our experience using small silicone molds, as in the case with the aforementioned stratigraphic micro ceramic-sample, has also been satisfactory with the surface finish micro samples of the archaeological and historical walls. This is due to its easy demolding, although it must be considered that curing raises a little temperature, which can be transmitted to the base of the mold that must be made of a resistant material (Figure 10). Regarding the different proportions of powder and catalyst of the previously used autoclave acrylic resin, a fast curing resin, in this case we have obtained the best results by mixing one part of resin powder with two of the catalyst or liquid monomer of the type auto cross linked. The cross-link is an additive whose main function is to promote a better union between the molecules of acrylic (molecular crossing), improving their mechanical properties. Adding to the monomer (auto or thermo polymerizable liquid) in the appropriate proportion during industrialization, offers the professional a better result in the quality of their work since the cross union reduces the porosity in the acrylic, becoming more waterproof and guaranteeing a more resistant to impact, flexion and abrasion. ${ }^{19}$

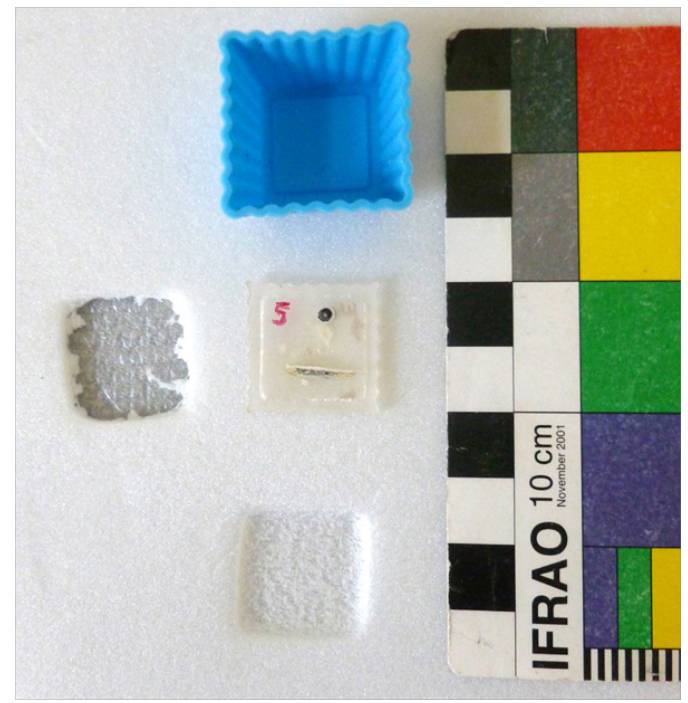

Figure 10 The blue silicone mold is observed with the test piece achieved. It contains a black reference moss and one of the micro samples taken at the surface finish of a wall at the end of 19th century to the beginning of the 20th century. You can also see the traces left by the mold on the polystyrene support, product of the heating of the acrylic mixture during curing.

There are precedents that successfully propose the superposition of layers of acrylic powder, catalyst, sample, powder and catalyst as many times as necessary to complete the desired height of the specimen. ${ }^{17,18}$ In our experience, this method causes many bubbles due not only to the porosity of our sample types, but also, because the catalyst does not always penetrate and evenly distribute with the powder in medium sized specimens (for example, $2 \times 2 \mathrm{~cm}$ ) and with samples of ceramic materials, including those in this case, and which are larger than $5 \mathrm{~mm}$ square. In this sense, it was more successful to mix a quantity of powder very well (either by means of a graduated spoon) with two equivalent parts in milliliters of catalyst (by means of 
a glass dropper) to achieve the expected transparency and the lowest or nil amount of bubbles.

The curing time depends absolutely on the amount of resin, as well as the proportions used for its conformation (depending on whether it is more or less liquid) and the ambient temperature. Ambient temperature, optimum moment of placement of the micro sample in the mold and setting time for curing were found as close related variables. Indeed, to decide the appropriate moment of the inclusion of the samples we have made different experiences. Thus, and following the general background mentioned above, in some cases we have first formed a base of acrylic resin at the bottom of the mold and after a few minutes place the sample, always using a hypodermic needle or clamp depending on the size of the sample, in position directly stratigraphic. Then we cover it with another portion of the acrylic mixture prepared later. In other cases, however, we have used only a prepared portion of acrylic to which after a few seconds we include the sample. This option was especially useful when the sample was really very small, of the order of $2 \mathrm{~mm}$. In this way, the samples were semi-submerged in the resin, enabling their "crimping" and easier polishing later.

Obviously, and even with the best mold option, which was that of the silicone mold, there is no recipe to indicate which is the optimum time to include the sample. This is due to the fact that, in addition to the density achieved in the step of resin preparation (in our case it is almost liquid), we must consider the time when the mixture starts to set (in our case and with this type of mixture usually begins to set between 30 seconds to the minute or minute and a half, when it already acquires some resistance to support the sample). But, it also depends on the ambient temperature since in our cases we have observed that at $24^{\circ} \mathrm{C}$ the setting goes well with the aforementioned times and gives us enough time to finish conditioning the sample in the mold. As we have anticipated, using molds of silicones does not require any type of release agent, so after the time of total curing, the specimen is easily demolded maintaining the ambient temperature at $24^{\circ} \mathrm{C}$ and at approximately 30 minutes in our case. Once dry, the test piece should be polished with sandpaper to water of different granulometry, starting from coarse to very fine grains, in order to expose evenly the micro stratigraphy to be analyzed. If what you intend is to analyze the micro stratigraphy included by SEM, as well as perform elemental analysis with them using an EDS Spectrometer coupled to this type of microscope, polishing could be avoided to the point of exposing the micro stratigraphy. However, if one starts, as usual, using optical microscopy (TM, PM or CM), it is convenient to expose the micro stratigraphy by polishing. In this way, in our experimentation we have successfully used a succession of sandpapers of different grains ranging from $150,320,600,1000$ and 1500 . This sanding process cannot be measured since it depends on another series of variables subject to the operator and that refer to the force used in sanding, the direction of the same, among the main ones. For this reason, it is necessary to verify at each step how the sample is exposed to high magnifications as in the case of the use of a TM.

\section{Discussion of results and conclusion}

The analysis of this type of stratigraphic micro-sample is linked to the study of what is known as ceramic materials in broader terms. ${ }^{20}$ That includes from different types of mud with which a brick or preHispanic, Colonial or Republican ceramic piece is made up to the techniques and properties of their different products, including the socalled advanced ceramic materials. Therefore, and in relation to this case study on archaeological and historical brick walls in particular, the broad definition of Mari ceramic materials as "non-metallic inorganic" also applies to surface finishes and to different pigment compositions of the pictorial layer (s), as well as the charges added thereto. In the wall of Buenos Aires case study's and as can be observed with the naked eye in Figure 9, the mortar of the brick wall that was shelled is composed of brick powder as a binder material, lithic sand and very small fragments of brick as aggregate materials. Traditionally, it has been suggested that these last two types of aggregate materials would fulfill a double function: that of avoiding contractions in the setting stage and of achieving the desired volume.

In accordance with the general objective of this work, consisting of obtaining stratigraphic micro-samples from the finishes of wall surfaces we proceeding to the inclusion one portion of the sample obtained in advance (Figure 10). For this, it was previously and carefully examined under a TM in order to account the number of layers and their relational positions. After that, it was included and sanded, with the precaution of re-observing the specimen under a microscope every time it was sanded using a different grain of sandpaper. This was especially important in the last instances, which only worked with the finest grain sandpapers (1000 and 1500), in order to expose the sample evenly and without missing any pieces. The following figures $11 \& 12$ are images taken at $20 \mathrm{X}$ with Arcano Tri Ocular Magnifier, model ZTX 1:4. The registration was carried out by means of a digital camera Motic, model Moticam 352.

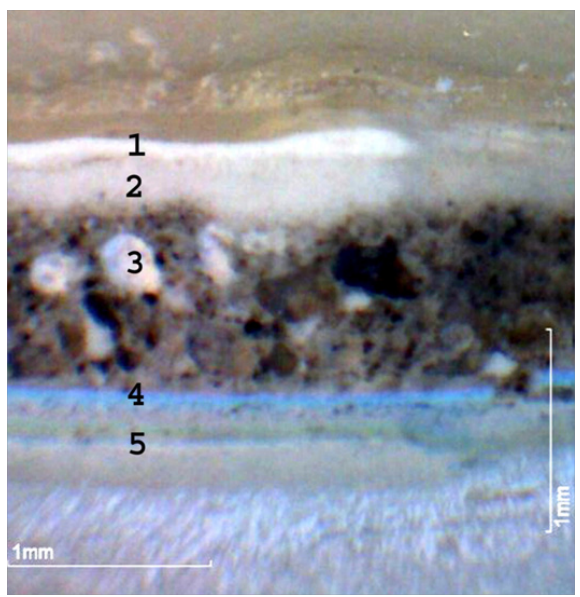

Figure I I Stratigraphic section of the Buenos Aires micro sample wall's at the end of 19th century to the beginning of the 20th century included in acrylic resin. TM 20X.

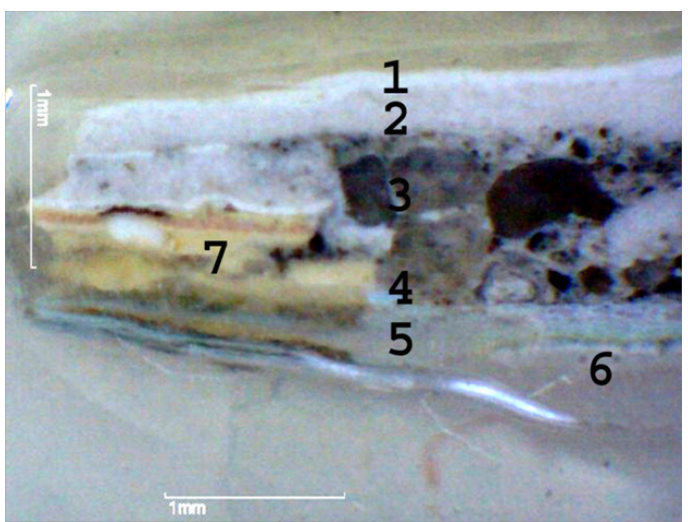

Figure 12 Other section of the same stratigraphic micro- sample, 20X. 
Figure 11, illustrates the stratigraphic section of the middle sector of the stratigraphic micro-sample included with final polishing, where the following can be observed in detail from top to bottom:

1. The final white coat of paint above coating layer 2 .

2. An off-white coating, which in turn is above plaster layer 3 .

3. A fine plaster placed above the old painted layer 4 .

4. Layer of celestial paint that in turn, at least in this sector of micro sample, is above layer 5 .

5. Fine grayish coating supported, apparently, directly above mortar layer 6 .

6. Mortar that acted as a "filling" of the wall composed of brick dust, lithic sand, and very small fragments of brick (it is not clearly seen in this portion of the stratigraphic micro-sample but it has remained on the edges).

Figure 12, on the other hand, illustrates the same stratigraphic micro-sample observed in further detail at one of its ends, leading to other sequence of strata or layers. In fact, from top to bottom, the layers can be observed in detail: 1,2,3,4,5,6 (only some loose grains) and 7, which would be an intrusive layer of yellow paint that would only have been preserved in some portions of that wall. In conclusion, we can summarize the advantages of this protocol of sampling, conservation and preparation of stratigraphic micro-samples including surface finishes of historic walls, as follows:

1. Guaranteeing not only the integrity of the micro sample while it is manipulated and/or transported but, in addition, the conservation for future studies on this topic.

2. Having the stratigraphic micro-sample included in resin with its surface well polishes and exposed, revealing the micro-structural and micro-morphological characteristics of the materials and the techniques utilized in the execution so that with enough contrast they can be both photographed and filmed. In this regard, the limit of the final scale for the observation will depend not only on the resolution of the microscope image system used, but also on the camera.

3. Easy manipulation of the micro-samples under the aforementioned conditions, for elemental and/or compositional characterization under different types of techniques that allow to identifying minerals, micro-lithic, elements, or pigment compounds present (PM, SEM-EDS or Raman Spectroscopy, among the characterization techniques available to us).

4. Finally, the conservation of the stratigraphic micro-sample is useful for observing and analyzing the sample as many times as needed, while creating a referential database. This is especially important in the case of stratigraphic micro-samples obtained from pieces that are difficult to access, such as those that are part of museum collections (Figure 8), located at a considerable distance, or that are part of a heritage building.

Similarly, among the main limitations of this protocol, the following can be listed:

1. At the time of sampling, it was sometimes difficult to recover a completely representative sample. In this sense, we agreed with Jiménez Roca, Ruiz Conde and Sánchez Soto (2005), that is was preferable to take a small but complete sample rather than a larger one that would be incomplete or would tend to fragment
2. It is also required some expertise in the procedure of inclusion and polishing of micro-samples, especially those of too small size (the size of the head of a pin), or in the case of those very despicable. Otherwise, it is possible to lose the only available piece from an archaeological structure sample. Therefore, even when dealing with very small sample sizes, it is very convenient to protect part of that micro-sample without including it. It is necessary to consider that in many cases, it is required to return those samples taken from pieces of collection to the institutions from where they were originally obtained, for the conduction of preferably non-destructive studies.

3. Finally, it has not been proven that acrylic resins, like the one used in this paper, dissolve organic elements that the microsample could contain.

In short, this protocol for sampling stratigraphic micro-samples of ceramic materials corresponding to walls of colonial or later times, constitutes a concrete proposal limited both to the characteristics of the structures sampled up to the moment but also to other parameters, including: the characteristics of the resin utilized, the ambient temperature, and the expertise of the manager who took the samples and made the inclusions. Nevertheless, the authors consider it is relevant to deepen information on these techniques of sampling, preparation and conservation of stratigraphic micro-samples provided they have been very frequently used in the fields of History of Art, Restoration and Conservation. The next step will be to experiment with the inclusion of others archaeological micro-samples already obtained, which will surely open not only new adjustments of these techniques but also new questions about the materials of the historic walls to be characterized.

\section{Acknowledgments}

I would like to thank all those who have collaborated in the different field work by helping me selflessly in the sampling. Especially, Dr. Fernando Marte, Magister Cristian López Rey and Architect Eduardo dos Santos. Special thanks also to Mr. Roberto Gabiassi, owner of the SV3 site and who allows us to continue researching on it. This essay has also been possible thanks to the preliminary advice of the Conservators Norma Pérez, Aldana Köller and to the support of CONICET

\section{Conflicts of interest}

Author declares that there is no conflict of interest.

\section{References}

1. Raehlmann E. Über die Maltechnik der Alten, mit besonderer Berücksichtigung der römisch-pompejanischen Wandmalerei, nebst einer Anleitung zur mikroskopischen Untersuchung der Kunstwerke. Berlin: G Reimer; 1910.

2. Plesters J. Section transversal and chemical analysis of paint samples. Studies in Conservation. 1956;1:110-157.

3. Sneyers R, I Thissen. La technique des lames minces appliquée at l'examen d'un relief assyrien en gypse. Bulletin de l'Institut Royal du Patrimoine Artistique. 1958;1:94-95.

4. Coremans P, J Thiessen. L'Introduction des lames minces dans I'examen des peintures. Bulletin de l'Institut Royal du Patrimoine Artistique. 1959;II:41-45.

5. Vallín AM, R Falchetti. La exploración de pintura mural. Una estratigrafía vertical. Boletin del Museo de Oro. 1990;28:107-118. 
6. Montes Bernárdez, JM Cabrera Garrido. Estudio estratigráfico y componentes pictóricos del arte prehistórico de Murcia (Sureste de España). Anales de Prehistoria y Arqueología. 1991-1992;7-8:69-74.

7. Cabrera Garrido JM, MC Garrido Pérez. Preparación de muestras para el examen microscópico de una pintura. $4^{\circ}$ Congreso de Conservación de Bienes Culturales. 1982;29.

8. Ojeda Calvo R, MA Tabales Rodríguez. La investigación arqueológica en Bienes Inmuebles. Metodología aplicada en la Puerta de Córdoba de Carmona. PH Boletín. 1996;15:41-52.

9. Sepúlveda M, E Laval. Aplicación y aplicabilidad de métodos físicoquímicos para el estudio de las pinturas rupestres. Ejemplo de estudio en la localidad del Río Salado (Norte de Chile). Resúmenes del XVII Congreso Nacional de Arqueología Chilena. 2010;II:825-834.

10. Castro Concha A. Objeto pictórico colonial: la consistencia de una forma de ser pintura. Conserva. 2010;14:5-22.

11. López MA, GA De La Fuente, D Fiore. Arqueometría del arte: estudios físicoquímicos de pigmentos arqueológicos. Boletín Del Museo Chileno de Arte Precolombino. 2012;17(2):75-81.

12. Barrio N, F Marte. Estudio material de la obra "Chacareros" de Antonio Berni. Ge Conservación. 2010;1:235-257.

13. Sepúlveda M. Pinturas rupestres y tecnología del color en el extremo sur de Chile. Magallania. 2011;39(1):193-210

14. Tomasini E, M Basile, N Ratto, et al. Evidencias químicas de deterioro ambiental en manifestaciones rupestres: un caso de estudio del oeste tinogasteño (Catamarca, Argentina). Boletín Del Museo Chileno de Arte Precolombino. 2012;17(2):27-38.

15. Marte F, DVJ Acevedo, N Mastrángelo. Técnicas arqueométricas combinadas aplicadas al análisis de diseños de alfarería 'tricolor' de Quebrada de Humahuaca, Jujuy, Argentina. Boletín del Museo Chileno de Arte Precolombino. 2012;17(2):53-64.

16. López MA. Uso combinado de Microscopía Óptica, Microscopía Confocal y Microscopía de Barrido Electrónico con Espectrómetro de Rayos X Dispersivo en Energías para el análisis de materiales cerámicos históricos. Mundo de Antes. 2015;9:99-120.

17. Martiarena X. Conservación y Restauración. Cuadernos de Sección. Artes Plásticas y Documentales. 1992;10:177-224.

18. Jiménez Roca E, A Ruiz Conde, PJ Sánchez Soto. Preparación de secciones estratigráficas: aspectos prácticos del análisis de estratos en obras del Patrimonio Cultural (pigmentos y soportes). Boletín de la Sociedad Española de Cerámica y Vidrio. 2005;44(6):382-386.

19. López MA. Microestratigrafías de acabados de superficie de muros históricos. Propuesta de protocolo de muestreo y preparación para su análisis y conservación. In: Resúmenes del XIX Congreso Nacional de Arqueología Argentina. Tucumán: Argentina; 2016. p. 910-917.

20. Mari E. Los materiales cerámicos. Un enfoque unificador sobre las cerámicas tradicionales y avanzadas, los vidrios, los cementos, los refractarios y otros materiales inorgánicos no metálicos. Librería y Editorial Alsina: Buenos Aires; 1998. 